\title{
SUSTAINABILITY AND RESILIENCE IN THE REHABILITATION OF ROAD INFRASTRUCTURES AFTER AN EXTREME EVENT: AN INTEGRATED APPROACH
}

\author{
Marinella Giunta \\ Dept of Civil, Energy, Environmental and Material Engineering, Mediterranea University of Reggio Calabria, \\ 89100 Reggio Calabria, Italy \\ E-mail:marinella.giunta@unirc.it
}

\begin{abstract}
For road infrastructures, the concepts of sustainability and resilience are becoming more and more relevant. The sustainability is closely linked with the concept of development that meets the needs of the present without compromising the ability of future generations to meet their own needs. The resilience is usually connected with the occurrence of extreme events or unusual disturbances (earthquake, landslide, floods) during the life cycle of infrastructures and refers to their ability of recover the previous functionality. Usually, the two concepts that account for two desired qualities of the infrastructures are applied following separate approaches. Better choices in road design, maintenance and rehabilitation should lead to an improvement of both qualities. On the other hand, an in deep analysis of the sustainability and resilience demonstrates a significant number of similar characteristics. In the light of the above premises, in the present paper, the suitability of an integrated approach in the choice of the rehabilitation alternatives after an extreme event is evaluated. A method to assess the sustainability, based on life cycle costs, and to estimate the resilience is setup. It resulted that an integrated perspective can be pursued and both resilience and sustainability allow addressing an appropriate amount of technical, economic and environmental/social issues and can lead to identifying the most efficient solution of rehabilitation.
\end{abstract}

Keywords: extreme event, life cycle cost analysis, rehabilitation, resilience, road, sustainability.

\section{Introduction}

Construction, operation, and rehabilitation of road infrastructures result in significant environmental impacts. Air pollution, energy consumption, noise, land occupancy, exploitation of natural resources, accidents are noteworthy impacts to take into account. On the other hand, during the service life, the capability of a road to withstand to a singular perturbation is a fundamental property to guarantee the assigned functionality. In road construction and rehabilitation both the concepts of sustainability and resilience are becoming more and more relevant.

The sustainability in design and management is currently dominating the research and the practical interests in the different topics of the road engineering. The concept of sustainability rose to prominence in the late 1980s and became a central issue in world politics. Brundtland et al. (1987) in the report Our Common Future defines for the first time the model of sustainable development, as "the development that meets the needs of the present without compromising the ability of future generations to meet their own needs". Sustainability is a model characterized by a holistic view and brings together three dimensions: ecology, economy, and society (Bocchini et al. 2013).

Another important concept, connected to the occurrence of extreme events during the life cycle of an infrastructure, is the resilience. In general, the resilience is a measure of the ability of a system to withstand an extraordinary event and to recover efficiently and rapidly the damage induced by such event. In the case of road infrastructures, the resilience refers to the ability to deliver a certain service level even after the occurrence of an extreme event and to recover their proper functionality as fast as possible.

Usually, the two concepts that account for two desired qualities of the infrastructures, are applied following separate approaches, few attempts to combine the two concepts can be found in the literature (Bocchini et al. 2013, Zinke et al. 2012). However, an in deep analysis of the sustainability and resilience demonstrates a significant number of similar characteristics. In fact, both concepts address a holistic view and deal with the assessment of an infrastructure system, by using economic and social categories as a base for measurement. Further, the instruments and the 
calculation methods applied for the evaluation are similar: Life Cycle Assessment (LCA), Life Cycle Cost Analysis (LCCA), Multi-Criteria Analysis (MCA) can efficiently address both the concepts. Finally, both concepts have assumed in the recent years a great importance in research and practice. Better choices in road design, maintenance and rehabilitation should lead to an improvement of either these qualities.

In the light of the above premises, in the present paper, the suitability of an integrated approach in the choice of the rehabilitation alternatives after an extreme event is evaluated. A method to assess the sustainability, based on the assessment of life cycle costs, and to estimate the resilience is also proposed.

\section{Sustainability: concept and approach}

The sustainability is associated to the definition provided by the World Commission on Environment and Development, 1987: “... development that meets the needs of the present without compromising the ability of future generations to meet their own needs .... However, there is no mathematical theory embodying these concepts, although one would be immensely valuable in humanity's efforts to manage the environment. The idea of sustainability applies to integrated systems comprising humans and the rest of nature (Cabezas et al. 2005).

The idea of sustainability for the road should be addressed not just in the design of infrastructures, but also in the rehabilitation, reuse or optimisation of existing infrastructures. This way to operate complies with the principles of urban sustainability and global sustainable development.

Trustworthy design and management need to balance social, economic and environmental issues. Obviously, the sustainable infrastructures should lead to improving socio-economics.

The three dimensions or pillars, internationally accepted as a well-established framework for the conceptual model of sustainability, are: economic, ecological, and social (Otto 2007). Economic viability concept relates to the public finance and is based on the financial and economic assessment of investments. Environmental sustainability builds on the externalities framework. Social sustainability draws from public policy framework where service delivery, governance, and social equity are critical (Reddy et al. 2014).

Achieving sustainability on these three dimensions is a challenge.

Often in current practice, the economic decisions far outweigh environmental and social decisions in the construction industry where the choices are usually made to maximize both short and long-term profits. In the light of this evidence, the successful implementation of sustainability is highly dependent on the ability and facility to measure and estimate environmental, societal and longterm economic variables, and convert them into benefits and costs (Chong et al. 2007). Even if most practitioners are persuaded of the importance of the sustainability, the deficiency of convincing data and calculations methods hamper its application during the decision-making stage. On the other side, it is also difficult to convince investors that increasing initial expenditure could benefit them in the long run.

In this context, LCA and LCCA are effective tools to assess the sustainability of road construction and rehabilitation. In the following, a brief description of these tools is provided.

According to Set (1993) LCA allows:

1. to evaluate the environmental burdens associated with a product, process, or activity by identifying and quantifying energy and materials used and wastes released to the environment;

2. to assess the impact of energy and materials used and releases to the environment;

3. to identify and evaluate opportunities to affect environmental improvements. The assessment includes the entire life cycle of the product, process or activity, encompassing, extracting and processing raw materials; manufacturing, transportation, and distribution; use, re-use, maintenance; recycling, and final disposal.

Typical life cycle assessment parameters include:

- Material Usage, the amount of material used expressed in its mass and volume;

- Embodied Energy the amount of energy required for extraction, processing, manufacturing, transportation, and assembly of building materials;

- $\mathrm{CO}_{2}$ Emissions, the emission of carbon dioxide, that contributes to global warming;

- Air Pollution, sulphur dioxide, nitrous oxides, methane, particulate and volatile organic compounds;

- Solid Waste Generation, the solid waste generated during manufacturing and construction;

- Water Pollution, the quantity of water use associated with a material process, including the effluent deposited into water bodies;

- Environmental Costs, externalities connected with construction.

Life Cycle Costing (LCC) is one of the best tools available to assess the benefit and cost of the infrastructure construction. It involves financial forecasts of infrastructure performance based on construction, operation and maintenance/renewal costs. This technique relies on the time value of money and expresses the infrastructure life cycle cost as a net present value. In other words, the total cost of construction, operating and maintaining the infrastructure is expressed as a single sum of money needed today to cover these costs over the study period selected for the life cycle costing exercise. Monetized externalities can be factored into this type of assessment to express the performance of the infrastructures in currency (Praticò, Giunta 2016a; Praticò, Giunta 2016b).

The main drawbacks of LCA, LCCA methods are the time and costs needed for the execution of a rigorous 
assessment. In some cases, data referred to the parameters listed above are missing or incomplete. There are also difficulties in the representation of environmental impacts among alternatives. For this last aspect, the use of Eco profile (Fig.1) can simplify the interpretation of life cycle assessments. However, there may be problems in achieving consensus on thresholds of sustainability. To construct an Eco profile, it should address the following aspects: select life cycle parameters, perform analyses to obtain impacts and then convert units of impact measurements ( $\mathrm{kg}$ to

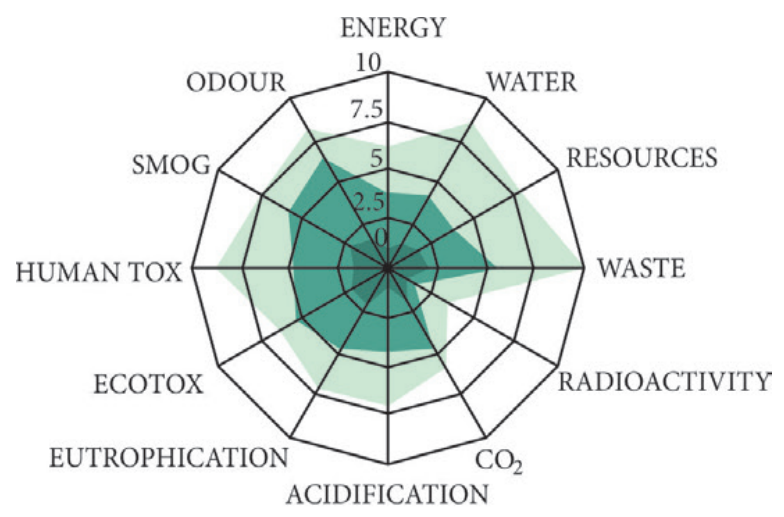

SUSTAINABLE

FEASIBLE

CONVENTIONAL

Fig. 1. Example of Eco profile to represent Environmental Impacts of Buildings (Peuportier 2001)

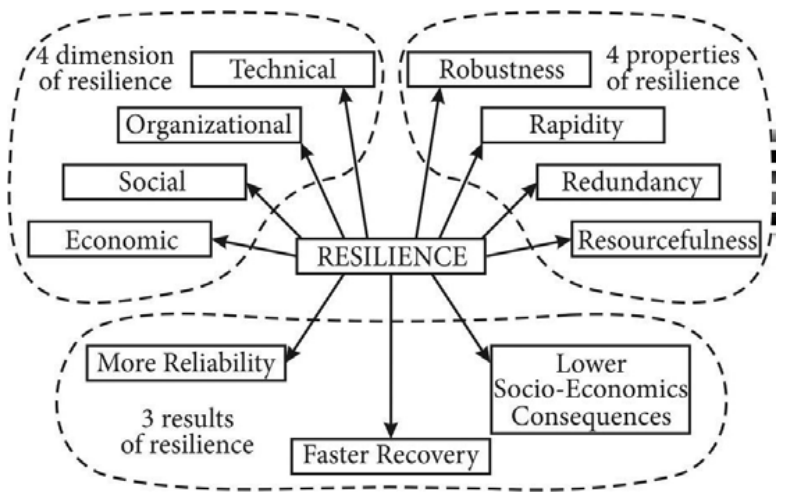

Fig. 2. Aspects of resilience (Bruneau et al. 2003)

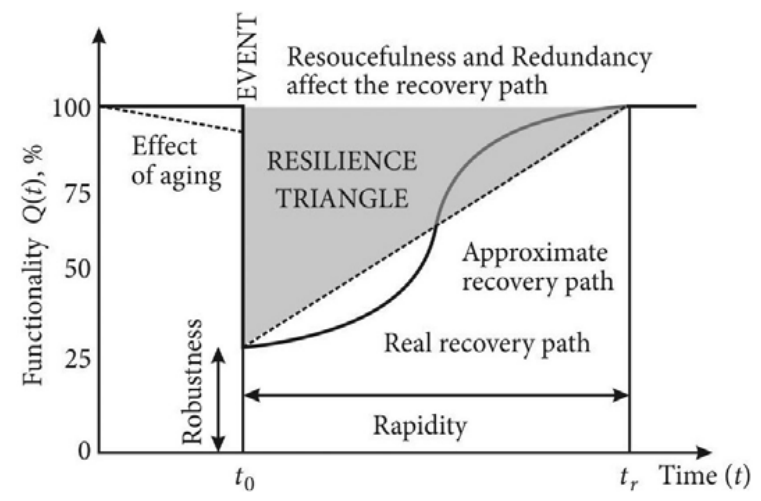

Fig. 3. Resilience and its properties tonnes) to fit within the scale of Eco profile. The number of parameters selected determines the number of sides of the polygon (Peuportier 2001).

\section{Resilience concept and measures}

The concept of resilience accounts for eleven aspects:

1. four main properties (Robustness, Redundancy, Resourcefulness and Rapidity);

2. four main dimensions (Technical, Organizational, Social and Economic);

3. three main results (More Reliability, Lower SocioEconomics Consequences, Fast Recovery) (Bocchini et al. 2014; Bruneau et al. 2003) (Fig.1).

As for the main properties:

- Robustness accounts for the reduced probability of degradation or loss of function in the event of disturbance or extreme event;

- Redundancy refers to the duplication of critical components or functions of a system with the aim of increasing reliability;

- Resourcefulness is the capacity to identify problems, establish priorities, and apply material (i.e. monetary, physical, technological, and informational) and human resources in the process of recovery to meet established priorities and achieve goals;

- Rapidity is the capacity to meet priorities and achieve goals promptly to contain losses, recover functionality and avoid future disruption.

Figure 3 graphically illustrates the properties of the resilience (Zhang, Wang 2016), and highlights the mutual interdependence, i.e. Rapidity in recovery the functionality depends on Resourcefulness and Redundancy.

Regarding the dimensions of resilience:

- Technical dimension includes all the aspects related to the construction and other technological aspects and refers to the ability of the physical system to guarantee acceptable/desired level of performance post critical event;

- Organizational dimension considers the capacity of the organization that manages the infrastructure to make decisions and take actions useful to achieve greater Robustness, Redundancy, Resourcefulness, and Rapidity;

- Social dimension involves the impact on community and the mitigation measures;

- Economic dimension refers to the direct and indirect costs deriving from the reduction of the functionality and the rehabilitation.

Outcomes of resilience are:

- More Reliability: lower probability for the infrastructure to reach limit states;

- Fast recovery, namely the rapidity with which the functionality is re-established during a disaster; this is a paramount characteristic of resilient systems;

- Low Socio-Economic Consequences, this outcome is guarantee by both probabilities of low service level reduction and fast recovery. 
It should be noted that any resilience-based analysis and decision require a quantitative measure of the system performance (Zhang, Wang 2016). The performance of a transportation network can be measured by different metrics, e.g. flow capacity (Nagurney, Qiang 2007), connectivity (Chen et al. 2002; Clark, Watling 2005), and travel time (Asakura, Kashiwadani 1995; Chen et al. 2007). However, these metrics are mainly used to measure network performance under normal service conditions and are inadequate in reflecting the network susceptibility to disruptive, lowprobability high-consequence natural and human-made hazards or its resilience (earthquakes, floods, terrorist attacks). More recently, other metrics have been proposed to measure the capability of the network after a disaster:

- used post-disaster connectivity and traversal cost among multiple origin-destination pairs in a network (Peeta et al. 2010);

- coverage and transport accessibility (Chang, Nojima 2001);

- pathway redundancy among all origin-destination pairs (Ip, Wang 2011).

\section{Objective of the work}

In the light of the above considerations, the aim of the present paper is the proposal of an integrated sustainabilityresilience based approach in the assessment of different rehabilitation alternatives after an extreme event. The integrated perspective embodying both resilience and sustainability allows addressing an appropriate amount of technical, economic and environmental/social issues and can lead to identifying the most efficient solution of rehabilitation. To this purpose a method to evaluate the sustainability, based on life cycle costs, and to estimate the resilience from the monetary standpoint is setup.

\section{Integrated approach}

The integrated approach sustainability - resilience in the rehabilitation of an infrastructure after an extreme event here proposed allows identifying which alternative, resulting in the lowest total cost and high performance to perturbation in post-event life, is the most suitable solution for the rehabilitation.

The approach is articulated in three main steps:

- Step 1: Identification of the rehabilitation alternatives;

- Step 2: Estimate of life cycle cost of each alternative;

- Step 3: Estimate of the resilience, in monetary terms, of a given infrastructure for each rehabilitation alternative.

Regarding the Step 1, for the identification of the rehabilitation alternatives, it is important to consider technical, economical and time issues. As for the technical problems, it is important to take into account the following aspects, if inherent to the solution of rehabilitation:

- horizontal/vertical alignment;

- type of embankment (materials, geometry);

- type of tunnel;
- type of bridges (steel beams, cement precast beams, span);

- type of pavement, safety barriers, signs and other tools for safety.

The identification of the alternatives to putting in comparison should also consider the costs of construction and the time required to restore the functionality of the infrastructure (Pratico et al. 2011; 2013). Based on the preliminary consideration of these elements some solutions can be considered inappropriate as alternatives and thus excluded in the successive analyses.

In Step 2, for each alternative, an estimate of the sustainability can be performed based on methods such as LCA and LCCA. In the proposed approach the LCCA is considered and applied. Life Cycle Cost Analysis is an engineering economic analysis tool that allows quantifying all the costs associated with a given option of the project (new project or rehabilitation project). Life Cycle Cost Analysis considers agency expenditures, for construction, operation, maintenance, disposal and user costs (delays produced by work zones, vehicle expenses) throughout the life of an alternative. A comprehensive LCCA analysis should also consider the environmental costs, for example regarding $\mathrm{CO}_{2}$ emissions, energy consumption, Global Warming Potential.

By reviewing and estimating all costs during the life span, LCCA allows to determine and demonstrate the economic merits of design alternatives analytically and consequently helps transportation agencies to identify the most sustainable solution (Giunta 2016; Giunta, Praticò 2017; Praticò, Giunta 2016a; 2016b).

Regarding the evaluation of the resilience for the given rehabilitation alternative, Step 3, it is important to consider:

1. the need to monetize this property, for an easy consideration in the decision-making processes;

2. the consideration of the main events that can create a perturbation and affect the functionality of the infrastructures;

3. the probability of occurrence of these events. Each infrastructure, based on its proper features (a type of alignment, type of embankment, type of bridge, type of tunnel), in the case of extreme events, behaves differently regarding the loss of functionality and consequently regarding time and cost to restore the previous level of functionality.

The cost to restore the functionality, namely the cost of reconstruction of the road infrastructures or its parts after an extreme event, and the time needed for reconstruction, which greatly affects the costs supported by the users, can be efficiently used to evaluate the resilience in monetary terms. It should be noted that the cost to restore mainly considers inside two of the main properties of the resilience, Robustness and Redundancy, (the higher Robustness and Redundancy, the higher the reconstruction cost), while time to restore considers the Resourcefulness and the Rapidity. 
The rebuilding after an extreme event also produces environmental impacts that should be monetised for a comprehensive cost evaluation. These costs are different and additional costs concerning the ones related to the service life of the infrastructure in normal conditions.

Figure 4 shows a diagram of the proposed integrated approach. The model to estimate the costs for sustainability and resilience is explained in the following.

Based on the LCCA approach, the cost of the sustainability, $C_{s u s}$, of a given rehabilitation alternative can be evaluated as:

$$
C_{s u s}=C_{a g}+C_{u s}+C_{e n v},
$$

where $C_{a g}$ - the cost of the agency for construction, operation, maintenance, and disposal, $C_{u s}$ - refers to the expenditure of the user for delays produced by maintenance activities and $C_{e n v}$ - the cost of environmental burdens due to the construction and maintenance activities.

These costs are related to different periods of the life of an infrastructure; therefore, to various alternatives at a given period, it is necessary to discount them. To this aim, the present value $(P V)$ of the cost can be adopted. Present Value is calculated as follow:

$$
P V_{j}=C_{j}\left(\frac{1+i}{1+r}\right)^{n}
$$

where $P V_{j}$ is the Present Value of the $j^{\text {th }}$ cost $\left(C_{j}\right), i$ is the inflation rate, $r$ is the interest rate, and $n$ is the $n^{\text {th }}$ year of the service life.

Based on this assumption, the total present value $(T P V)$ of sustainability is:

$$
T P V_{\text {sus }}=P V_{a g}+P V_{u s}+P V_{e n v} .
$$

The total present value can be evaluated during the service life of an infrastructure. Life Cycle Cost Analysis enables to assess the trends of $T P V$ during the time.

On the contrary, the evaluation of the resilience should emphasize the impact of the infrastructure damage, failure, and recovery when subject to hazards characterised by a low probability of occurrence and potentially high consequences. In this sense, it is possible to associate to each considered alternative the cost of the total recovery of functionality in case of a later undesired event. The expenditure for recovering the functionality is discontinuous during the service life because it is related to the occurrence of an extreme event. A probability of occurrence characterises each event. Consequently, the impact of an extreme event regarding the expenditure to recover the functionality of an infrastructure or its part should be evaluated as follow:

$$
C_{r e s}=\sum_{i} P_{i} C_{r e s, i},
$$

where $P_{i}$ is the probability of occurrence of the event $i$; and $C_{r e c, i}$ is the cost for the recovery of the functionality after the event $i$.

The cost for the recovery of the functionality encompassed the three classes of cost considered for the sustainability and namely, the agency cost for reconstruction of the infrastructure, the user cost, and the environmental cost.

$$
C_{r e s, i}=C_{r e c, i}+C_{u s, i}+C_{e n v, i}
$$

where $C_{r e c, i}$ is the cost of reconstruction after the event $i^{\text {th }}$, $C_{u s, i}$ is the cost supported by the users for the loss of functionality and $C_{e n v, i}$ is the environmental cost associated with the reconstruction. It should be noted that:

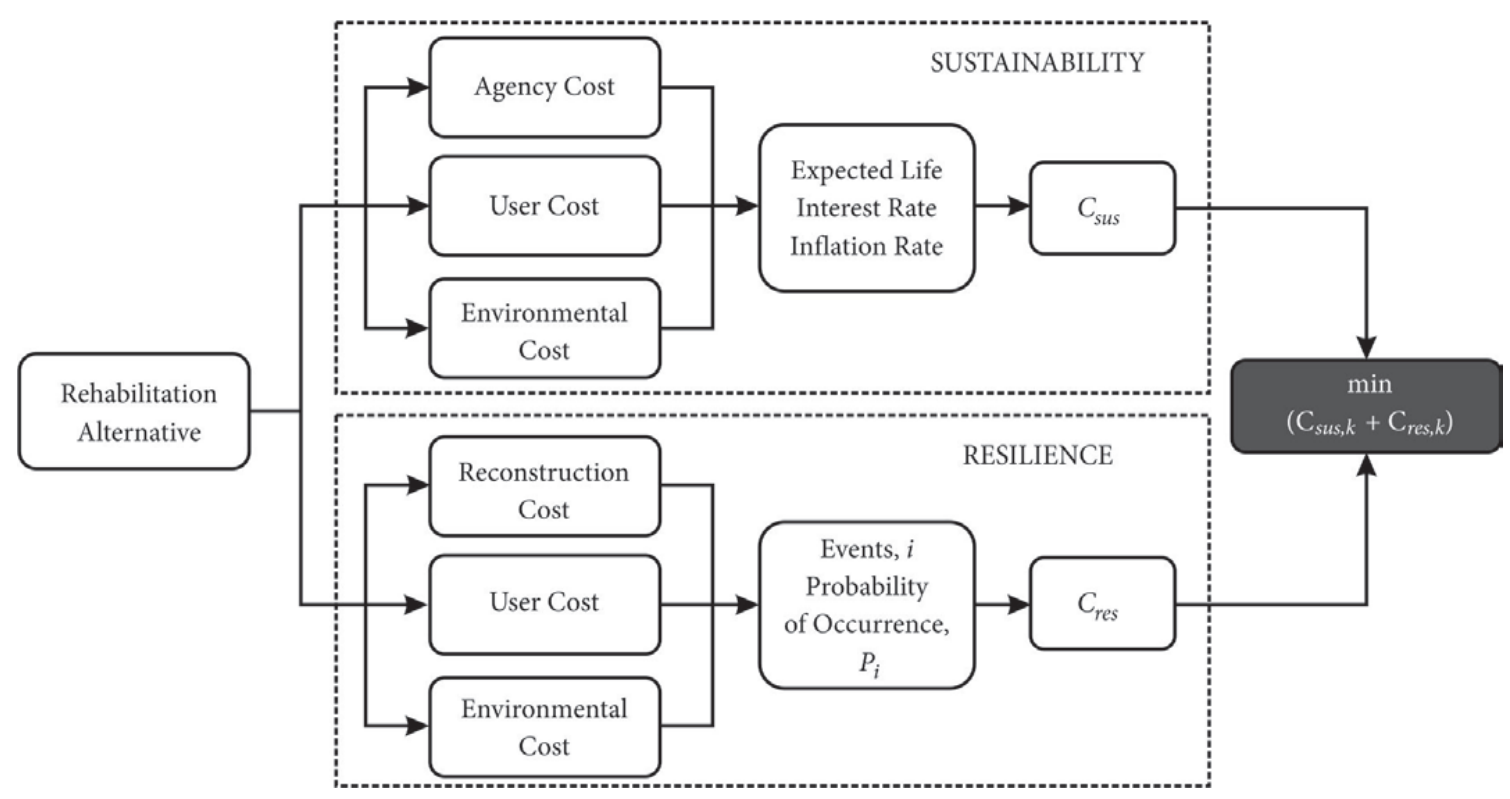

Fig. 4. Diagram of the proposed integrated approach 
- the cost of reconstruction depends on the level of resistance that it would achieve in the rehabilitated infrastructure (the higher the resistance, Robustness, and Redundancy, the higher the reconstruction cost);

- the user costs are related to the delays for slowdowns or journey of alternative routes, and it should be addressed at the scale of the transportation network. According to Bocchini et al. (2013), they can be evaluated as follow:

$$
\begin{aligned}
C_{u s}= & {\left[N_{\text {car }}\left(C_{\text {time }, \text { car }}+C_{\text {oper,car }}\right)+N_{\text {truck }}\right.} \\
& \left.\left(C_{\text {time }, \text { truck }}+C_{\text {oper,truck }}\right)\right] T_{\text {rec }} t_{\text {delay }},
\end{aligned}
$$

where $N_{c a r}$ and $N_{\text {truck }}$ refer to the daily number of cars and tracks affected by the limitation of traffic, $C_{\text {time,car }}$ and $C_{\text {time,truck }}$, are respectively the time cost for cars and trucks; $C_{o p e r, c a r}$ and $C_{\text {oper,truck }}$ - operation costs per hour for cars and trucks; $T_{r e c}$ is the time in days needed for the reconstruction and the recovery of functionality; $t_{\text {delays }}$ is the delay in hours supported by the users.

The activities connected to the rehabilitation of the infrastructures (material productions, transportation, and landfill) also produce environmental impacts that can be quantified for example regarding $\mathrm{CO}_{2}$ emissions (Giunta 2016; Giunta, Praticò 2017; Praticò, Giunta 2016a; 2016b).

$$
C_{e n v}=\sum_{k} \sum_{j} Q_{k j} U P_{k j}
$$

where $Q_{k j}$ - the quantity of the $j^{\text {th }}$ impact due to the $k^{\text {th }}$ process and $U P_{k j}$ - the unit cost of the impact.

The choice of the best solution of rehabilitation can be pursued based on the sum of the costs of sustainability (Equation 3) and resilience (Equation 4) using the monetization of the two most important aspects about each alternative.

$$
T C_{k}=T P V_{s u s, k}+C_{r e s, k} \text {, }
$$

where $T C_{k}$ - the total cost related to the $k^{\text {th }}$ alternative while $T P V_{\text {sus }, k}$ and $C_{r e s, k}$ are respectively the discounted costs related to the sustainability and the cost of resilience.

The lower total cost could bring to identify the best rehabilitation strategy. Following the proposed approach, the most important aspects associated with sustainability and resilience assessment are considered at the same time and in the process of mutual interaction.

\section{Conclusions}

1. Resilience and sustainability are two qualities of the infrastructure that should be pursued at the same time when decisions are made regarding the design, maintenance, and management of infrastructure systems even if in some case the pursuit of resilience can conflict with the pursuit of sustainability.
2. The consideration of these two qualities can help in the identification of the best strategy of the rehabilitation of an infrastructure or its part also after an extreme event. Nowadays natural disasters (earthquakes, landslides, floods) are getting more frequent importance, and thus the resilience assessment of the infrastructures and the selection of the most effective recovery strategies is essential.

3. The main challenge in the evaluation of sustainability and resilience of a transport infrastructure is the quantitative measure of these qualities.

4. In this paper, an integrated approach is proposed and a method to estimate in monetary terms the sustainability and the resilience of a given rehabilitation alternative after an extreme event is set-up.

5. For the estimation of sustainability the Life Cycle Cost Analysis has been efficiently applied.

6. For the resilience, an accurate estimate of the costs of reconstruction, depending on the level of resilience that it would like achieved, of the user costs, due to the loss of functionality of the infrastructures, and of the environmental costs, related to the reconstruction activities, help to evaluate a given alternative from this standpoint.

7. The approach proposed seems useful to address a complete evaluation of different design/rehabilitation alternatives. Practical applications of the approach are ongoing.

\section{References}

Asakura, Y., Kashiwadani, M. 1995. Traffic Assignment in a Road Network with Degraded Links by Natural Disasters, Journal of the Eastern Asia Society for Transportation Studies 1(3): 1135-52.

Bocchini, P.; Frangopol, D.; Ummenhofer, T.; Zinke, T. 2013. Resilience and Sustainability of Civil Infrastructure: Toward a Unified Approach, Journal of Infrastructure Systems 20(2): 04014004. https://doi.org/10.1061/(ASCE)IS.1943-555X.0000177, 04014004

Brundtland, G.; Khalid, M.; Agnelli, S.; Al-Athel, S.; Chidzero, B.; Fadika, L.; Singh, M. 1987. Our Common Future ('’Brundtland Reportl'). Oxford University Press, Oxford.

Bruneau, M.; Chang, S. E.; Eguchi, R. T.; Lee, G. C.; O’Rourke, T. D.; Reinhorn, A. M.; Shinozuka, M.; Tierney, K.; Wallace, W. A.; von Winterfeldt, D. 2003. A Framework to Quantitatively Assess and Enhance the Seismic Resilience of Communities, Earthquake Spectra 19(4): 733-752. https://doi.org/10.1193/1.1623497

Cabezas, H.; Pawlowski, C. W.; Mayer, A. L.; Hoagland, N. T. 2005. Sustainable Systems Theory: Ecological and Other Aspects, Journal of Cleaner Production 13(5): 455-467. https://doi.org/10.1016/j.jclepro.2003.09.011

Chang, S. E.; Nojima N. 2001. Measuring Post-Disaster Transportation System Performance: the 1995 Kobe Earthquake in Comparative Perspective, Transportation Research Part A: Policy and Practice 35(6): 475-494. https://doi.org/10.1016/S0965-8564(00)00003-3

Chen, A.; Kim, J.; Zhou, Z.; Chootinan, P. 2007. Alpha Reliable Network Design Problem, Transportation Research Record 2029: 49-57. https://doi.org/10.3141/2029-06

Chen, A.; Yang, H.; Lo, H. K.; Tang, W. H. 2002. Capacity Reliability of a Road Network: an Assessment Methodology and 
Numerical Results, Transportation Research Part B: Methodological 36(3): 225-252. https://doi.org/10.1016/S0191-2615(00)00048-5

Chong, W. K.; Pokharel, S. K.; Leyden, C. 2007. A Proposed Application of Using LCCA to Measure Cost of Sustainable Design, in Proc. of the Inaugural Construction Management and Economics "Past, Present and Future" Conference CME25, 16-18 July, 2007, Reading, United Kingdom. 519-526.

Clark, S.; Watling, D. 2005. Modelling Network Travel Time Reliability under Stochastic Demand, Transportation Research Part B: Methodological 39(2): 119-140. https://doi.org/10.1016/j.trb.2003.10.006

Giunta, M. 2016. Assessment of the Sustainability of Traditional and Innovative Rail Track System, in Proc. of International Conference on Traffic and Transport Engineering, 24-25 November, 2016, Belgrade, Serbia.

Giunta, M.; Praticò F. G. 2017. Design and Maintenance of HighSpeed Rail Tracks: a Comparison between Ballasted and Ballast-Less Solutions Based on Life Cycle Cost Analysis, in Transport Infrastructure and Systems: Proceedings of the AIIT International Congress on Transport Infrastructure and Systems, 10-12 April 2017, Rome, Italy. 87. https://doi.org/10.1201/9781315281896-14

Ip, W. H.; Wang, Q. 2011. Resilience and Friability of Transportation Networks: Evaluation, Analysis and Optimization, IEEE Systems Journal 5(2): 189-198. https://doi.org/10.1109/JSYST.2010.2096670

Nagurney, A.; Qiang, Q. 2007. A Network Efficiency Measure for Congested Networks, EPL (Europhys Lett) 79(3): 38005. https://doi.org/10.1209/0295-5075/79/38005

Otto, S. 2007. Bedeutung und Verwendung der Begriffe nachhaltige Entwicklung und Nachhaltigkeit: Eine empirische Stud$i e$, Dissertation, Jacobs University Bremen, Jacobs Center on Lifelong Learning and Institutional Development, Germany. (in German)

Peeta, S.; Sibel, S. F.; Gunnec, D.; Viswanath, K. 2010. Pre-Disaster Investment Decisions for Strengthening a Highway Network, Computers and Operations Research 37(10): 1708-1719. https://doi.org/10.1016/j.cor.2009.12.006
Peuportier, B. L. P. 2001. Life Cycle Assessment Applied to the Comparative Evaluation of Single Family Houses in the French Context, Energy and Buildings 33(5): 443-450. https://doi.org/10.1016/S0378-7788(00)00101-8

Praticò, F. G.; Giunta, M. 2016a. Assessing the Sustainability of Design and Maintenance Strategies for Rail Track by Means Life Cycle Cost Analysis, in Proc. of COMPRAIL $201615^{\text {th }}$ International Conference on Railway Engineering Design and Operation, 19-21 July, 2016, Madrid, Spain.

https://doi.org/10.2495/CR160231

Praticò, F. G.; Giunta, M. 2016b. Issues and Perspectives in Railway Management from a Sustainability Standpoint, DEStech Transactions on Engineering and Technology Research (ictim). https://doi.org/10.12783/dtetr/ictim2016/5529

Praticò, F. G.; Vaiaia, R.; Giunta, M.; Moro, A.; Iuele, T. 2013. Recycling PENs Back to TPLAs: It That Possible Notwithstanding RAP Variability? Applied Mechanics and Materials 253-255: 376-384.

https://doi.org/10.4028/www.scientific.net/AMM.253-255.376

Praticò, F. G.; Vaiana, R.; Giunta, M. 2011. Recycling PEMs Back To Innovative, Silent, Permeable Road Surfaces, in Proc. of $8^{\text {th }}$ International Conference on "Environmental Engineering", 19-20 May, 2011, Vilnius, Lithuania. 1186-1192.

Reddy, V.R., Kurian, M., Ardakanian, R. 2014. Life-Cycle Cost Approch for Management of Environmental Resources. A Primer. Springer ISBN 978-3-319-06286-0.

Set, A. 1993. Guidelines for Life-Cycle Assessment: a "Code of Practice". Society of Environmental Toxicology and Chemistry, Pensacola, Florida.

Zhang, W.; Wang, N. 2016. Resilience-Based Risk Mitigation for Road Networks, Structural Safety 62: 57-65. https://doi.org/10.1016/j.strusafe.2016.06.003

Zinke, T.; Bocchini, P.; Frangopol, D. M.; Ummenhofer, T. 2012. Combining Resilience and Sustainability in Infrastructure Projects, in Proc. of the $3^{\text {rd }}$ International Symposium on LifeCycle Civil Engineering, 3-6 October, 2012, Vienna, Austria. 2450-2457.

Received 08 March 2017; accepted 09 June 2017 